\title{
Perancangan Sistem Informasi Inventaris Barang Pada Sekolah Sma Negeri 4 Pematangsiantar
}

\author{
Victor Marudut Mulia Siregar \\ Politeknik Bisnis Indonesia, Pematangsiantar, Sumatera Utara \\ victor.siregar2@gmail.com
}

\begin{abstract}
The design of this inventory information system is carried out aimed at facilitating the recording of data items that are quite numerous and complicated and are still managed manually in SMA Negeri 4 Pematangsiantar city. The information system that is designed consists of several parts, namely: recording data where inventory, recording incoming goods, recording items out, mutation of goods and making reports of goods entered and reports of goods out. The implementation results of this inventory information system are recording inventory data and making inventory reports easier to do. With the existence of this inventory information system, the work of item inventory inventorying at Pematangsiantar State Senior High School 4 can be done more quickly and accurately.
\end{abstract}

Keywords—Information systems, waterfall, inventory, goods

\begin{abstract}
Abstrak
Perancangan Sistem informasi inventaris barang ini dilakukan bertujuan untuk mempermudah pencatatan data barang yang cukup banyak dan rumit serta masih dikelola secara manual pada SMA Negeri 4 kota Pematangsiantar. Sistem informasi yang dirancang terdiri dari beberapa bagian antara lain: pencatatan data tempat inventaris, pencatatan barang masuk, pencatatan barang keluar, mutasi barang serta pembuatan laporan barang masuk dan laporan barang keluar. Hasil implementasi dari Sistem informasi inventaris ini adalah pencatatan data inventaris serta pembuatan laporan inventaris lebih mudah untuk dilakukan. Dengan adanya sistem informasi inventaris barang ini, pekerjaan pendataan inventaris barang pada SMA Negeri 4 Pematangsiantar sudah dapat dilakukan dengan lebih cepat dan akurat.
\end{abstract}

Kata kunci-Sistem informasi, waterfall, inventaris, barang

\section{PENDAHULUAN}

Sistem informasi sangat dibutuhkan pada saat ini dalam meningkatkan pengawasan terhadap suatu pekerjaan sehingga lebih mudah untuk melakukan monitoring. Sebuah sistem informasi sangat mempengaruhi kemajuan kinerja karena melalui sistem informasi yang terbangun dapat memberikan informasi yang dapat terpercaya bagi para pengguna juga mempercepat pengaksesan data khususnya di zaman yang sangat maju ini perkembangan teknologi mengharuskan keberadaan sistem informasi sebagai salah satu sarana informasi [1]-[3], [4], [5].

SMA Negeri 4 Pematangsiantar adalah sekolah unggulan yang ada di kota Pematangsiantar dan saat ini sangat diminati oleh para pelajar di dalam kota maupun di luar kota Pematangsiantar. Sekolah ini dikenal sebagai sekolah yang bermutu dan berkualitas dalam menghasilkan siswa-siswi yang cerdas.

Inventaris merupakan daftar yang memuat semua barang milik kantor yang dipakai dalam melaksanakan tugas [6], [7]. Pada sekolah SMA Negeri 4 Pematangsiantar, 
pengolahan data inventaris seperti penyimpanan dan pencarian data inventaris barang masih kurang optimal karena sistem penyimpanan datanya masih dilaksanakan dengan melakukan pencatatan ke dalam buku besar, sehingga ketika terjadi perpindahan maupun kehilangan barang, maka petugas yang menangani iventaris barang kewalahan untuk mencari maupun menggantikan barang tersebut karena pencatatan barang yang kurang efektif.

Agar pencatatan inventaris barang pada SMA Negeri 4 Pematangsiantar lebih tepat dan akurat serta lebih mudah untuk dilakukan, maka dirancang suatu sistem informasi inventaris barang untuk dapat mendata keberadaan barang-barang tersebut.

Untuk mengatasi hal tersebut, maka dirancang sebuah sistem informasi inventaris barang dengan menggunakan bahasa pemograman Visual Basic Net dan database MySQL yang akan mempermudah pihak Sekolah SMA Negeri 4 Pematangsiantar dalam merecord data inventaris barang serta membuat laporan data inventaris per ruangan, laporan inventaris yang hilang dan inventaris yang rusak.

\section{METODE PENELITIAN}

Metode yang dilaksanakan dalam perancangan sistem informasi inventaris barang ini meliputi beberapa tahapan yaitu : pengumpulan data, perancangan sistem dan implementasi sitem.

Pengumpulan data dilakukan dengan observasi dan wawancara untuk memperoleh informasi mengenai pendataan inventaris barang yang terdapat pada sekolah SMA Negeri 4 Pematangsiantar. Pada tahap selanjutnya dilakukan perancangan sistem dengan membuat diagram DFD (Data Flow Diagram) dan dilanjutkan dengan membuat rancangan form dan laporan yang dibutuhkan. Setelah tahapan perancangan selesai dilakukan, dilanjutkan dengan tahap implementasi.

\subsection{Kebutuhan Hardware dan Software}

Untuk membangun Sistem Informasi Inventaris Barang pada Sekolah SMA Negeri 4 Pematangsiantar dengan hasil yang baik, hardware yang dibutuhkan adalah sebagai berikut: Komputer dengan Processor Standart Dual Core atau yang diatasnya, Memori minimal 2 GB, Harddisk dengan kapasitas minimal 500 GB.

Software yang dibutuhkan antara lain : Microsoft Visual Basic.Net sebagai aplikasi bahasa pemrograman, MySQL sebagai aplikasi pengolah database, Crystal Report sebagai aplikasi pengolah laporan.

\subsection{Perancangan DFD}

Rancangan proses dimodelkan dengan Data Flow Diagram (DFD). Penggambaran DFD dimulai dengan penggambaran konteks diagram. Diagram konteks dapat dilihat pada gambar 1. Diagram konteks digunakan untuk menunjukan semua alur data dari sistem informasi inventaris barang, dimulai dari petugas yang melakukan input data barang, input mutasi barang, input barang masuk, input barang keluar sampai kepada kepala sekolah yang menerima laporan inventaris barang. 
IT Journal Research and Development

Vol.2, No.2, Maret 2018

e-ISSN: 2528-4053

DOI : $10.25299 /$ itird.2018.vol3(1).1899

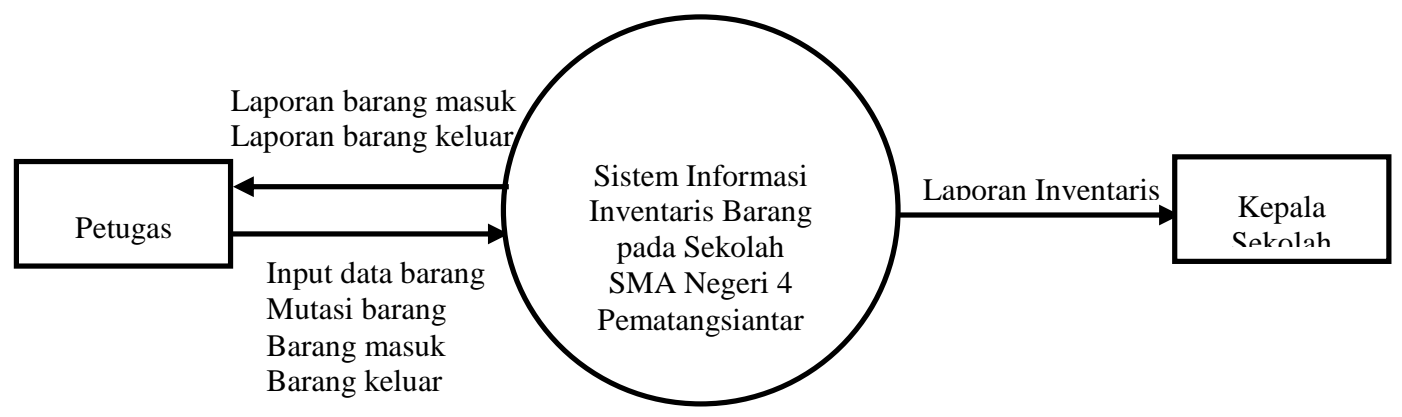

Gambar 1. Diagram Konteks

\subsection{Perancangan sistem}

Perancangan sistem dilakukan dengan membuat rancangan proses yang terdiri dari rancangan form input barang, form input barang masuk, form mutasi barang, rancangan laporan, dan rancangan database. Perancangan sistem yang dibuat antara lain :

\subsubsection{Form Input Barang}

Form Input barang adalah form yang digunakan untuk menginput data barang. Rancangan Form Input barang dapat dilihat pada gambar 2.

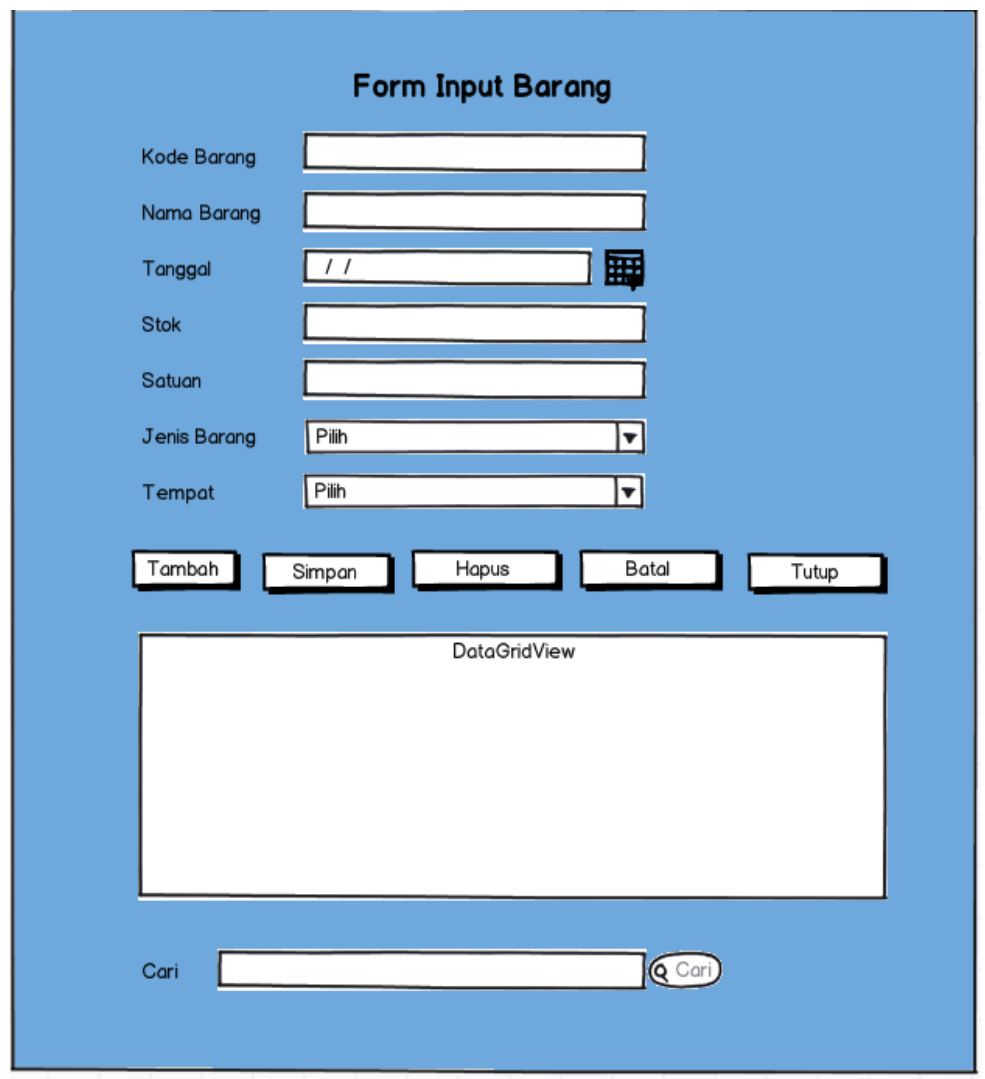

Gambar 2. Rancangan Form Input Barang 
IT Journal Research and Development

Vol.3, No.1, Agustus 2018

e-ISSN: 2528-4053

DOI : 10.25299/itjrd.2018.vol3(1).1899

\subsubsection{Form Input Barang Masuk}

Form Input Barang Masuk adalah form yang digunakan untuk menginput barang yang masuk. Adapun rancangan formnya seperti pada gambar 3 .

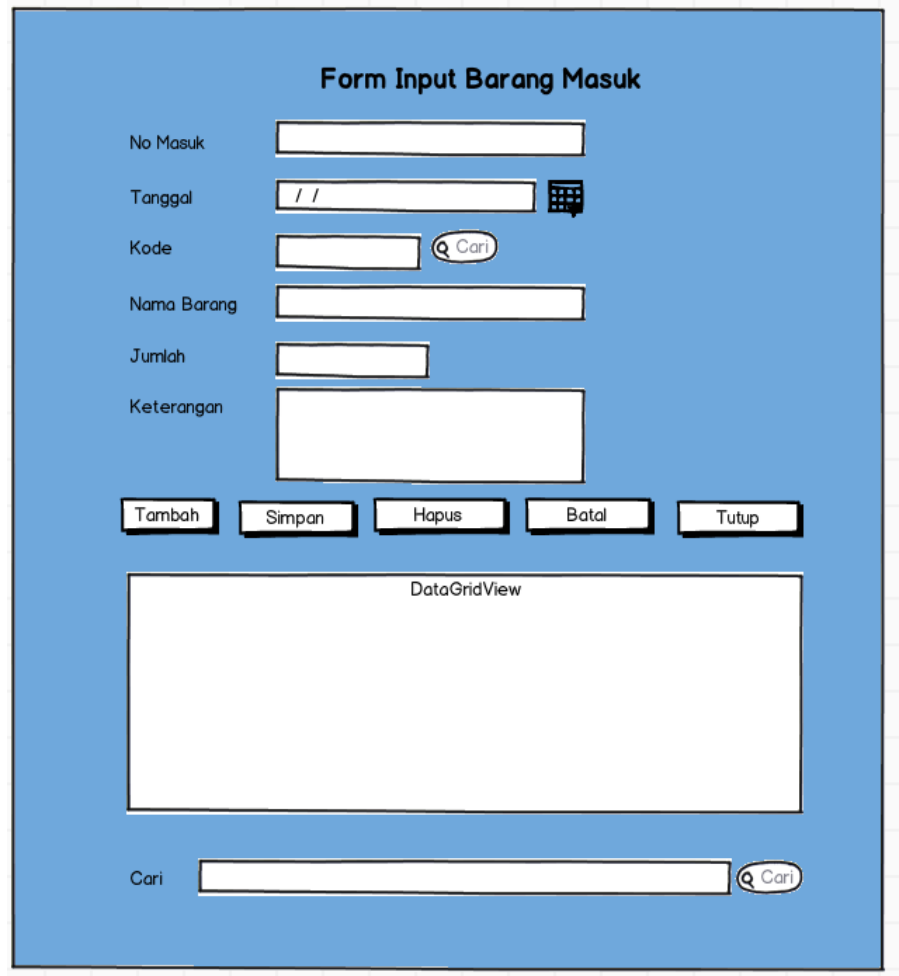

\section{Gambar 3. Rancangan Form Laporan Barang Masuk}

\subsubsection{Form Laporan Barang Keluar}

Form Laporan Barang Keluar adalah form untuk menampilkan data-data barang keluar yang akan dicetak. Rancangan form Laporan Barang dapat dilihat pada gambar 4.

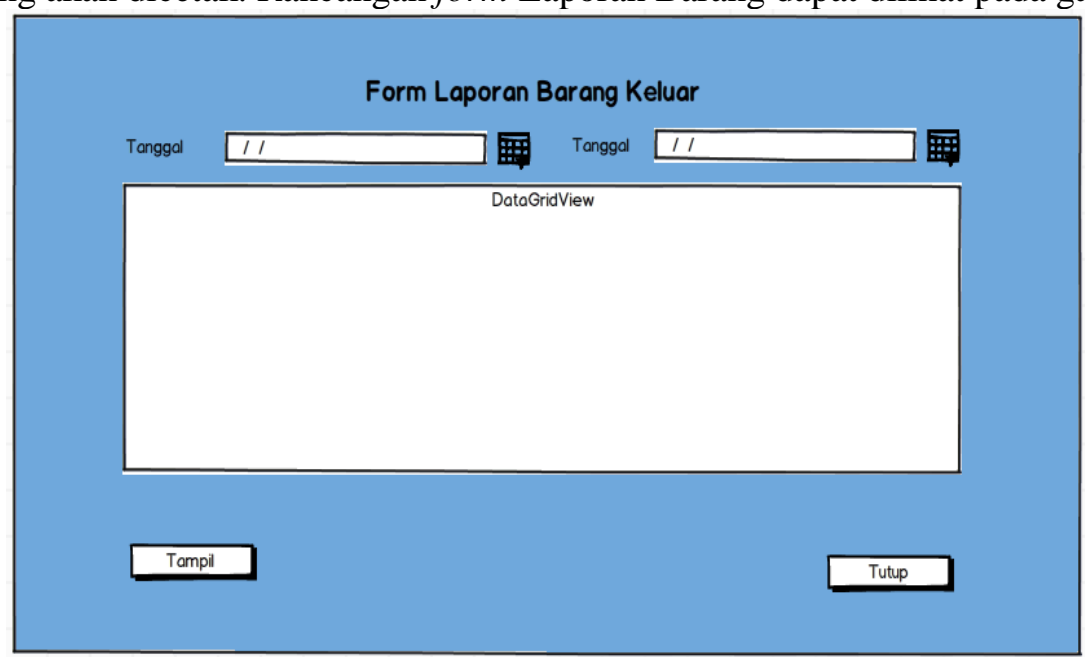

Gambar 4. Rancangan Form Laporan Barang Keluar

\subsubsection{Rancangan Laporan}

Rancangan laporan merupakan keluaran dari sistem berupa laporan-laporan hasil dari pengolahan data. Rancangan laporan seperti pada gambar 5. 
IT Journal Research and Development

Vol.2, No.2, Maret 2018

e-ISSN: 2528-4053

DOI : 10.25299/itjrd.2018.vol3(1).1899

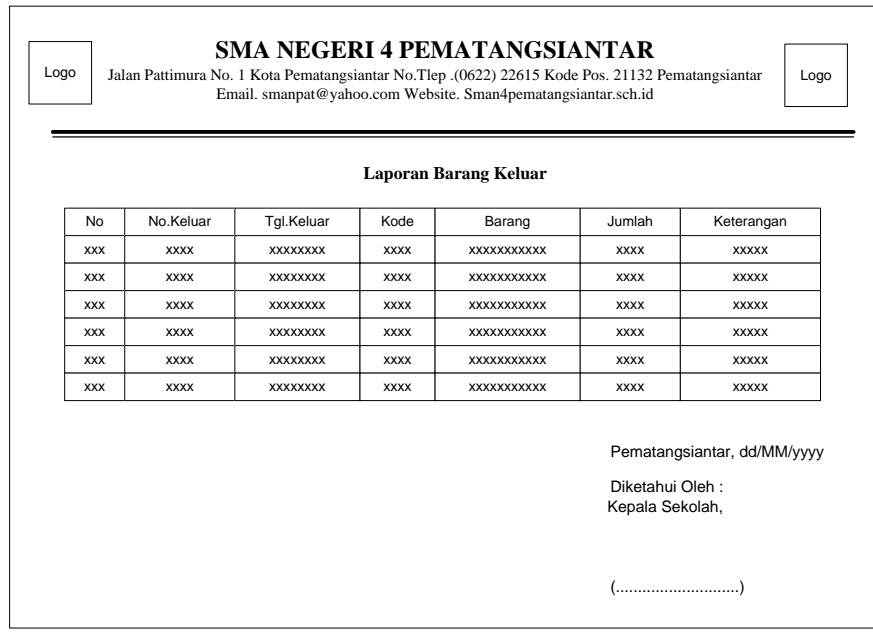

\section{Gambar 5. Rancangan Output Inventaris Barang}

\section{HASIL DAN PEMBAHASAN}

Setelah tahap perancangan sistem selesai dilakukan, tahap yang dilakukan selanjutnya adalah tahap implementasi. Hasil implementasi dari sistem informasi inventaris barang pada SMA Negeri 4 Pematangsiantar ini terdiri dari :

\subsection{Form Input Data Barang}

Form Input Data Barang digunakan untuk mengolah data Barang. Tampilan form Input Data Barang dapat dilihat pada gambar 6.

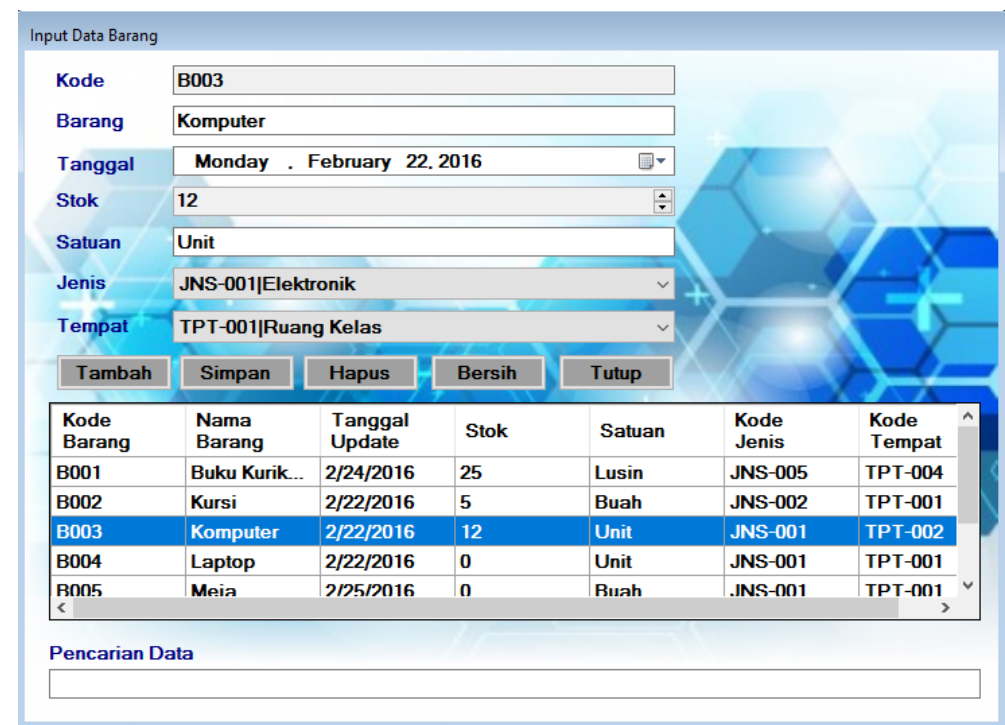

Gambar 6. Tampilan Form Input Data Barang 
IT Journal Research and Development

Vol.3, No.1, Agustus 2018

e-ISSN: 2528-4053

DOI : 10.25299/itjrd.2018.vol3(1).1899

3.2 Form Input Barang Masuk

Form Input BarangMasuk digunakan untuk mengolah data barang masuk.

Tampilan Input Barang Masuk dapat dilihat pada gambar 7.

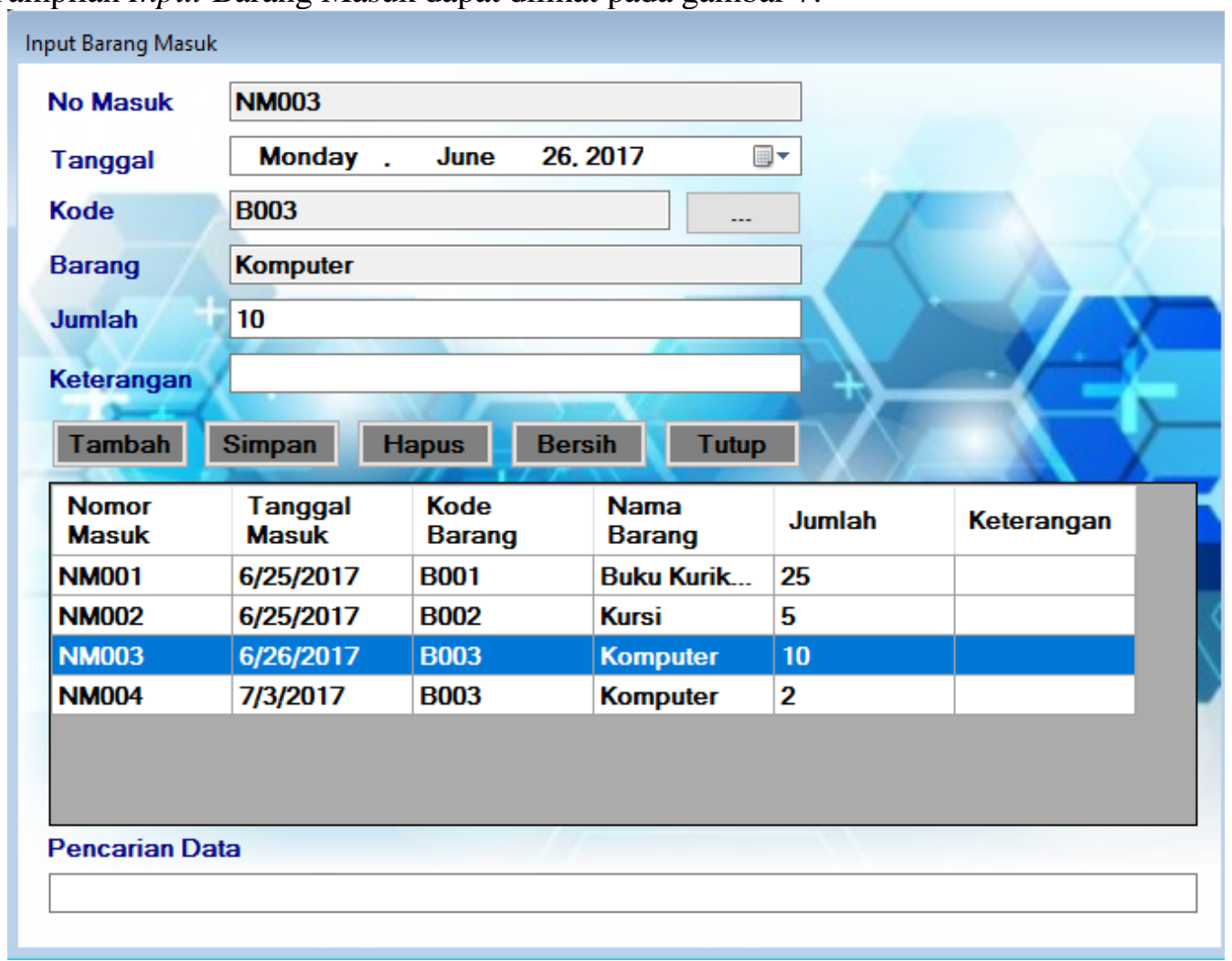

\section{Gambar 7. Tampilan Form Input Barang Masuk}

\subsection{Keluaran (Output) Sistem}

Keluaran (Output) Sistem dari Sistem Informasi Inventaris Barang ini adalah berupa Laporan Barang masuk dan barang keluar yang akan diberikan kepada pimpinan. Dengan adanya laporan ini, pimpinan dapat melihat barang dengan mudah, dan mengontrol pengeluaran barang bagi hal-hal yang tidak dibutuhkan

Laporan Barang masuk dan laporan barang keluar pada Sekolah SMA Negeri 4 Pematangsiantar dapat dilihat pada gambar 8 dan gambar 9 . 
IT Journal Research and Development

Vol.2, No.2, Maret 2018

e-ISSN: 2528-4053

DOI : 10.25299/itjrd.2018.vol3(1).1899

SMA NEGERI 4 PEMATANGSIANTAR

Jl. Patimura No 1 Kota Pematangsiantar Tlep. (0622) 22615 Kode Pos 21132 Pematangsiantar Email: smanpatayahoo.com Website : www.sman4pematangsiantarsch.id

LAPORAN BARANG MASUK

\begin{tabular}{|c|c|c|c|c|c|c|}
\hline NO & NO MASUK & TGL.MASUK & KODE & BARANG & JUMLAH & KETERANGAN \\
\hline 1 & 001 & 6/19/2017 12:00:1 & B001 & Buku Kurikulum & 100 & baik \\
\hline 2 & 002 & 6/19/2017 12:00:1 & B002 & Kursi & 100 & baik \\
\hline 3 & 003 & $6 / 19 / 2017 \quad 12: 00: 1$ & 8003 & Komputer & 5 & baik \\
\hline 4 & 004 & 6/19/2017 12:00:1 & 8004 & Laptop & 5 & baik \\
\hline
\end{tabular}

Pematangsiantar, 19 June 2017

\begin{tabular}{|c|c|}
\hline Yang Membuat Laporan. & $\begin{array}{l}\text { Pematangsiantar, } 19 \text { June } 2017 \\
\text { Disetujui Oleh : } \\
\text { Kepala Sekolah, }\end{array}$ \\
\hline NIP. & $\begin{array}{l}\text { RUDOL BARMEN MANURUNG, M.Pd } \\
\text { NIP.19661128 } 1998011001\end{array}$ \\
\hline Total Page No.: 1 & Zoom Factor: $100 \%$ \\
\hline
\end{tabular}

Gambar 8. Laporan Barang Masuk

\section{SMA NEGERI 4 PEMATANGSIANTAR}

JI. Patimura No 1 Kota Pematangsiantar Tlep. (0622) 22615 Kode Pos 21132 Pematangsiantar Email: smanpat@yahoo.com Website : www.sman4pematangsiantar.sch.id

LAPORAN BARANG KELUAR

\begin{tabular}{|c|c|c|c|c|c|c|}
\hline No & NO KELUAR & TGL.KELUAR & KODE & BARANG & JUMLAH & KETERANGAN \\
\hline 1 & NKO05 & 6/19/2017 12:00:0c & 8002 & Kursi & 30 & rusak \\
\hline 2 & NKD03 & 6/19/2017 12:00:00 & 8003 & Komputer & 2 & rusak \\
\hline 3 & NKOO4 & $6 / 19 / 2017 \quad 12: 00: 00$ & B004 & Laptop & 2 & Rusak \\
\hline
\end{tabular}

Pematangsiantar, 19 June 2017

Disetujui Oleh

Yang Membuat Laporan, Kepala Sekolah,

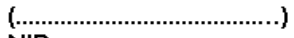

RUDOL BARMEN MANURUNG, M.Pd

NIP NIP.196611281998011001 


\section{KESIMPULAN}

Dari hasil implementasi yang telah diuraikan diambil beberapa kesimpulan, yaitu :

1. Dengan mengunakan sistem yang telah dibangun dengan menggunakan Visual Basic Net dan database MySQL tersebut, maka proses pengolahan, penyimpanan, dan pencarian Data Inventaris Barang pada Sekolah SMA Negeri 4 Pematangsiantar dapat dilakukan dengan lebih cepat.

2. Sistem yang telah dibangun dengan menggunakan Visual Basic Net dan database MySQL tersebut juga menghasilkan laporan Data Inventaris Barang Pada Sekolah SMA Negeri 4 Pematangsiantar yang lebih tepat dan akurat.

\section{SARAN}

Melalui implementasi Sistem Informasi Inventaris Barang pada Sekolah SMA Negeri 4 Pematangsiantar ini, ada beberapa saran untuk pengembangan antara lain :

1. Sistem Informasi Inventaris Barang pada Sekolah SMA Negeri 4 Pematangsiantar ini masih harus dikembangkan sesuai dengan kebutuhan yang uptodate.

2. Agar sistem ini dapat digunakan secara optimal maka sebaiknya perlu diperhatikan spesifikasi hardware dan software dari komputer yang dipakai untuk disesuaikan dengan spesifikasi yang dibutuhkan.

\section{DAFTAR PUSTAKA}

[1] A. Efendi, "Konsep Strategis Sistem Informasi Akademik Smart Card Universitas Islam Riau," IT J. Res. Dev., vol. 2, no. 1, pp. 32-42, 2017.

[2] E. Syam, "Rancang Bangun Sistem Informasi Manajemen Data Mahasiswa Dan Dosen Terintergasi," IT J. Reseach Dev., vol. 2, no. 2, pp. 45-51, 2018.

[3] A. F. Karami, "Manajemen Kualitas Data dan Informasi dengan Sistem Informasi untuk Meningkatkan Kinerja Operasional Pabrik PT . Sari Aditya Loka 2," IT J. Res. Dev., vol. 2, no. 2, pp. 1-13, 2018.

[4] V. M. M. Siregar, "Perancangan Website Sebagai Media Promosi Dan Penjualan Produk," TAM (Technology Accept. Model., vol. 9, no. 1, pp. 15-21, 2018.

[5] V. M. M. Siregar, "Sistem Informasi Pembelian Dan Penjualan Pakaian Pada Galoenk Distro Pematangsiantar," JurTI (Jurnal Teknol. Informasi), vol. 1, no. 2, pp. 219-227, 2017.

[6] F. Lazim, A. Wijaya, and Z. Arifin, "Digital Inventory Untuk Pendataan Barang Menggunakan Barcode Di Laboratorium Stt Nurul Jadid," in Sentia 2016, 2016, vol. 8, pp. 311-316.

[7] H. W. Luthfi and B. K. Riasti, "Sistem Informasi Perawatan Dan Inventaris Laboratorium Pada Smk Negeri 1 Rembang Berbasis Web," J. Speed - Sentra Penelit. Eng. dan Edukasi, vol. 3, no. 4, pp. 83-91, 2011. 